Electronic Supplementary Material (ESI) for Polymer Chemistry.

This journal is (C) The Royal Society of Chemistry 2021

\title{
PolyDODT: A Macrocyclic Elastomer with Unusual Properties
}

Kristof Molnar, ${ }^{a}$ Hojin Kim, ${ }^{b}$ Dongjie Chen, ${ }^{c}$ Carin A. Helfer, ${ }^{a}$ Gabor Kaszas, ${ }^{a}$ Gregory B. McKenna, ${ }^{c, d}$ Julia A. Kornfield, ${ }^{b}$ Chunhua

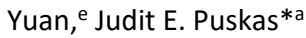

a. The Ohio State University, College of Food, Agricultural, and Environmental Sciences, Department of Food, Agricultural and Biological Engineering, 220

FABE, 1680 Madison Avenue, Wooster, $\mathrm{OH} 44691$

b. California Institute of Technology, Division of Chemistry and Chemical Engineering, Pasadena, CA 91125

c. Texas Tech University, Department of Chemical Engineering, Lubbock, TX 79409-3121

d. The Ohio State University, Campus Chemical Instrument Center, 496 W 12th Ave, Columbus, $\mathrm{OH} 43210$

e. North Carolina State University, Department of Chemical and Biomolecular Engineering, Raleigh, NC 27695-7905
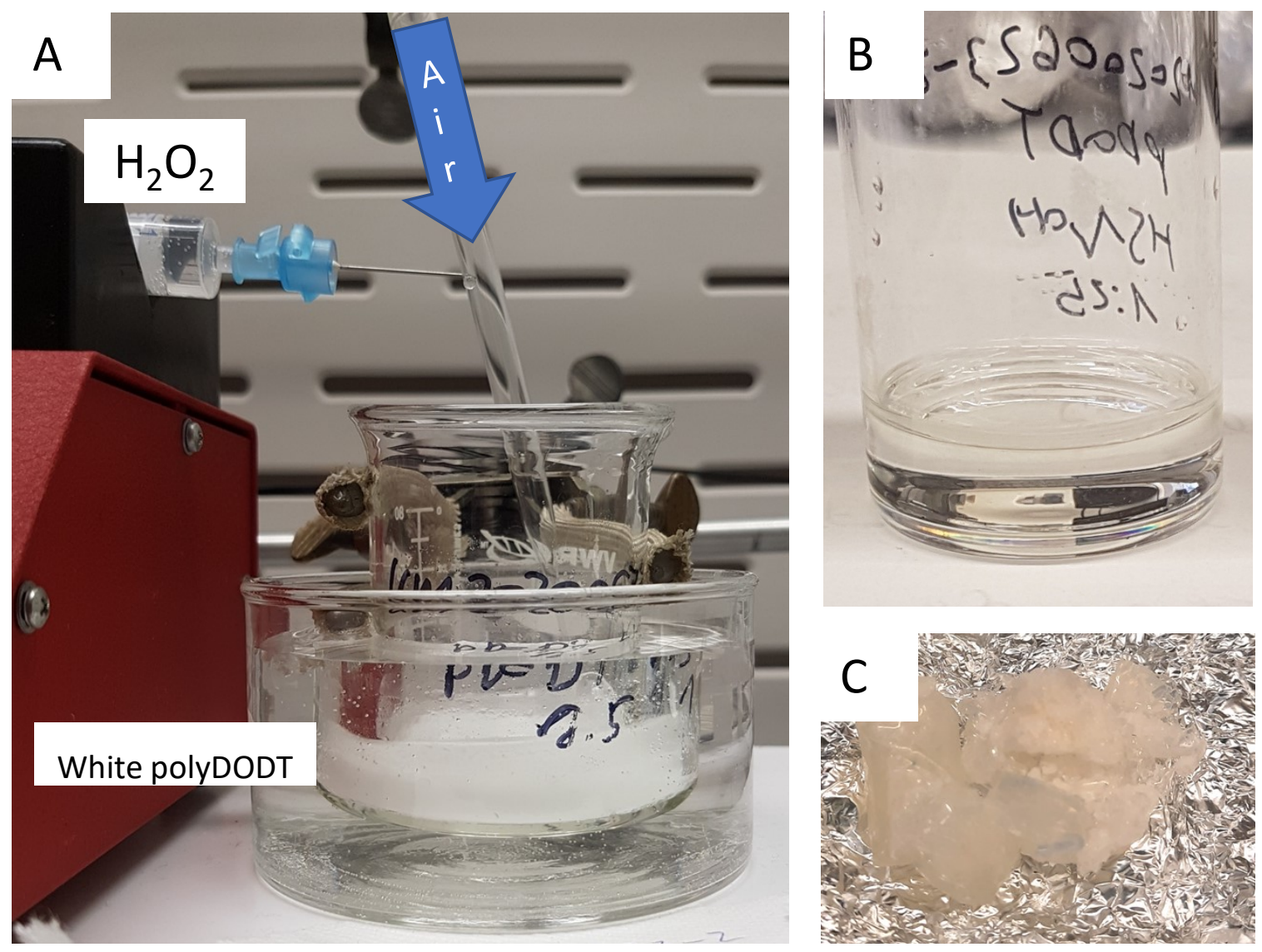

Figure S1. Setup for the synthesis of polyDODTs, where the precipitated white rubber is visible at the bottom of the beaker (A) and pictures of the final, water-clear low molecular weight (B) and high molecular weight (C) products after purification. 


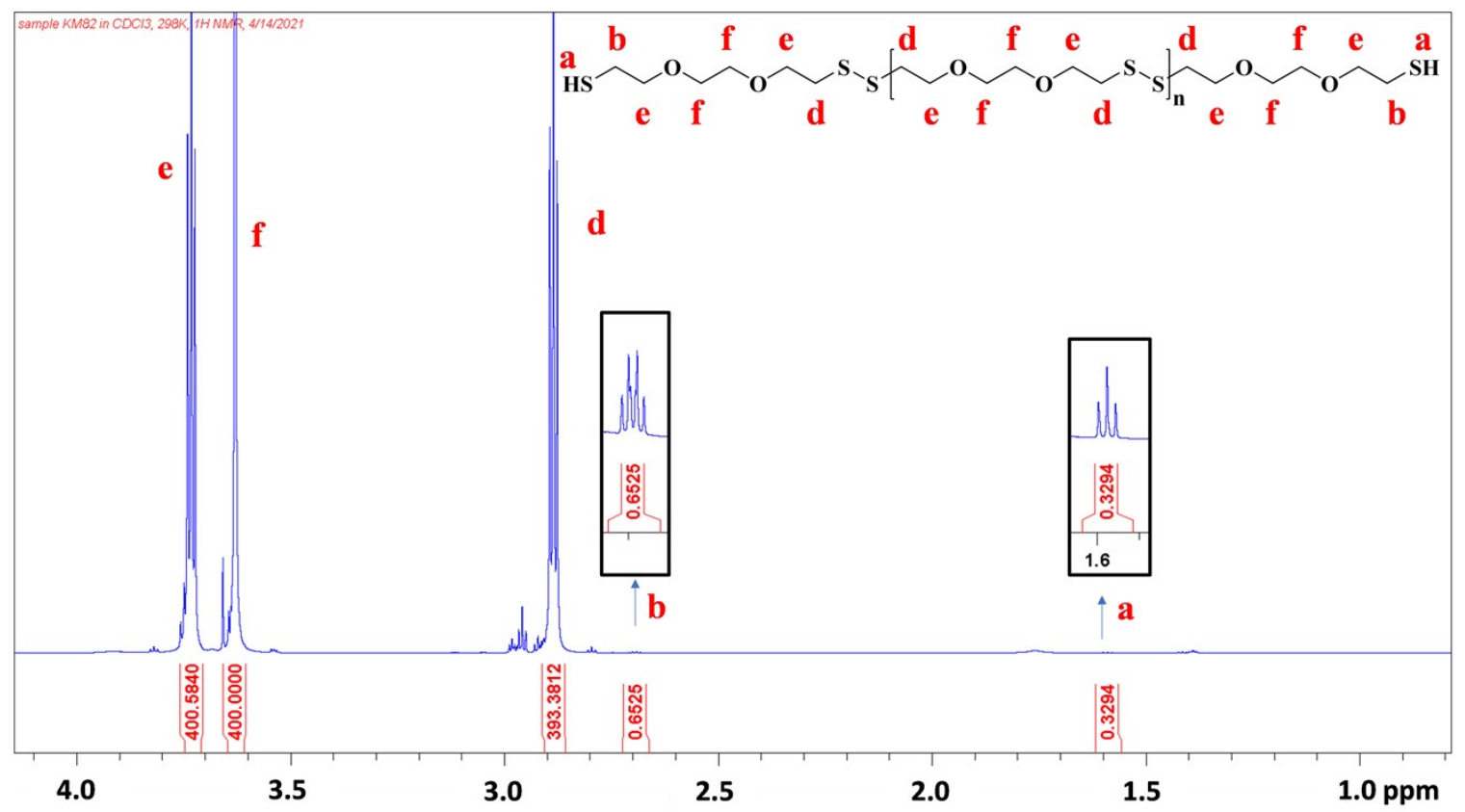

Figure S2. $800 \mathrm{MHz}{ }^{1} \mathrm{H} N M R$ of $L 2.2 M_{n}(N M R)=82,900 \mathrm{~g} / \mathrm{mol}$, Table 4). Scaling factor is 1 and for the insets it is 64 . Resonances of the main chain are $\mathrm{\delta H}\left(800 \mathrm{MHz} ; \mathrm{CDCl}_{3} ; \mathrm{CDCl}_{3}\right) 2.98\left(4 \mathrm{H}_{d}, \mathrm{t}, \mathrm{CH}_{2} \mathrm{SSCH}_{2}\right) ; 3.65\left(4 \mathrm{H}_{f}, \mathrm{~S}, \mathrm{OCH}_{2} \mathrm{CH}_{2} \mathrm{O}\right)$; $3.75\left(4 \mathrm{H}_{e}, t, \mathrm{OCH}_{2} \mathrm{CH}_{2} \mathrm{SSCH}_{2} \mathrm{CH}_{2} \mathrm{O}\right)$ ppm, while resonances related to the end group appear at $1.6(2 \mathrm{H}, t, \mathrm{SH})$ and $2.75\left(4 \mathrm{H}_{b}, q, \mathrm{CH}_{2} \mathrm{SH}\right) \mathrm{ppm}$.

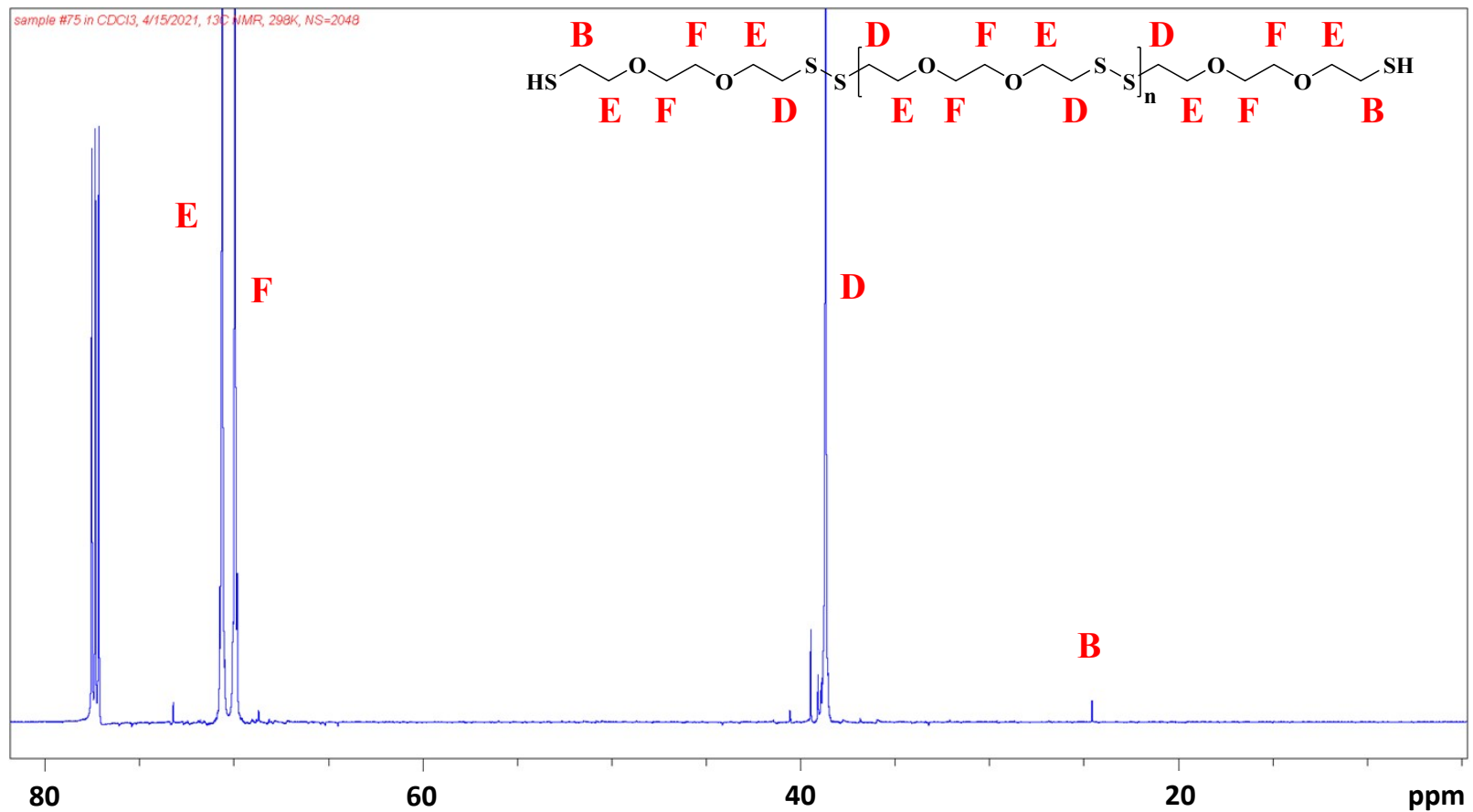

Figure S3. ${ }^{13} \mathrm{C} \mathrm{NMR}(700 \mathrm{MHz})$ of sample $\mathrm{L1.1}$. $\left(\mathrm{M}_{n}(\mathrm{NMR})=33,800 \mathrm{~g} / \mathrm{mol}\right.$, Table 4) in $\mathrm{CDCl}_{3}$. Scaling factor is 8 . The main chain carbon signals are $\delta \mathrm{C}\left(700 \mathrm{MHz} ; \mathrm{CDCl}_{3} ; \mathrm{CDCl}_{3}\right) 38.6\left(2 \mathrm{C}_{\mathrm{D}}, \mathrm{s}, \mathrm{CH}_{2} \mathrm{SSCH}_{2}\right) ; 69.9\left(2 \mathrm{C}_{\mathrm{F}}, \mathrm{S}, \mathrm{OCH}_{2} \mathrm{CH}_{2} \mathrm{O}\right) ; 70.6$ $\left(\mathrm{C}_{\mathrm{E}}, \mathrm{S}, \mathrm{OCH}_{2} \mathrm{CH}_{2} \mathrm{~S}\right)$ ppm, while a signal related to the methylene carbon next to the thiol end group can be seen at 24.6 ppm. 


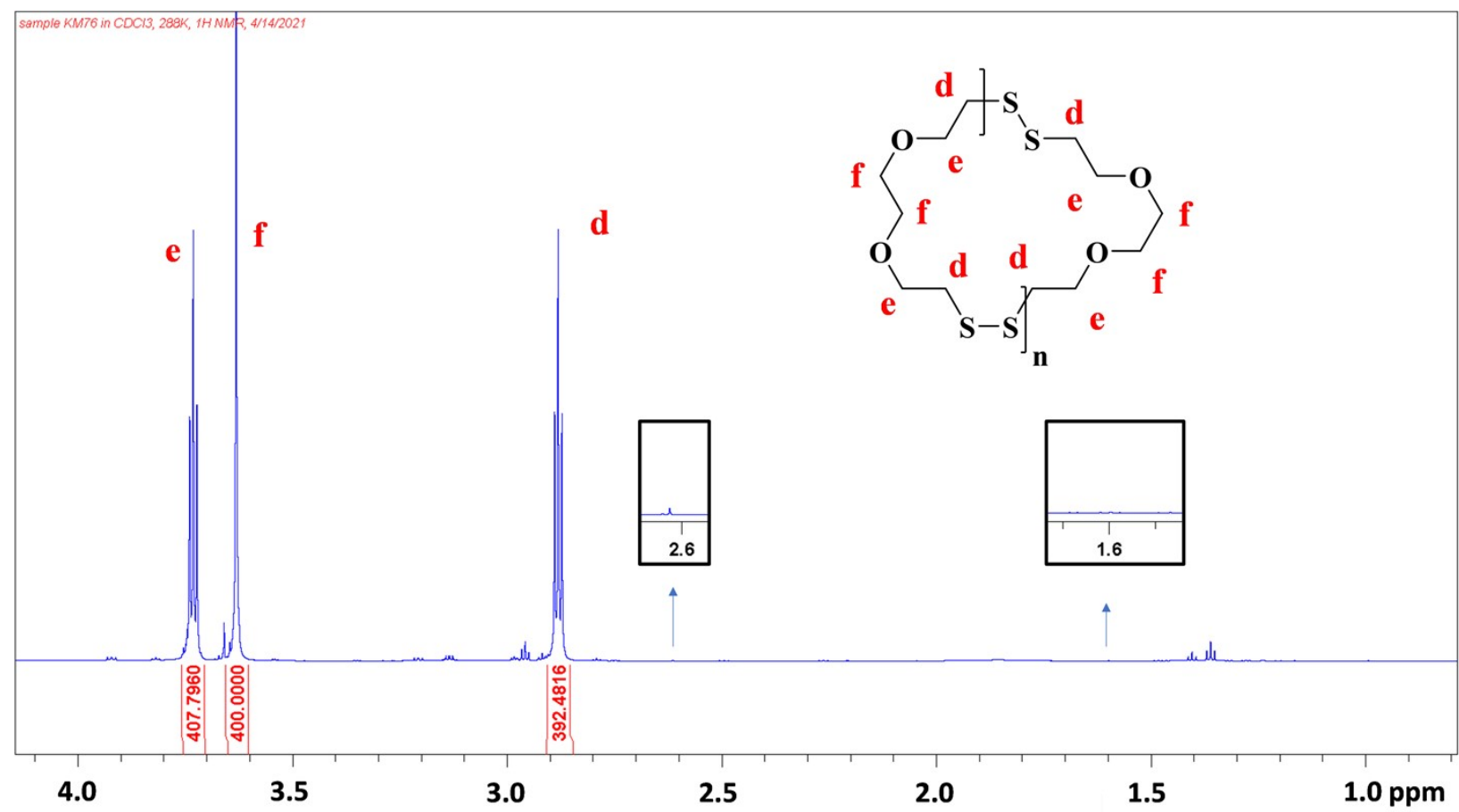

Figure S4. $800 \mathrm{MHz}{ }^{1} \mathrm{H} N M R$ spectrum of $C 3.1 \mathrm{M}_{n}(\mathrm{SEC})=35,800 \mathrm{~g} / \mathrm{mol}$. Insets: enlarged regions to show the absence of $-\mathrm{CH}_{2}-\mathrm{SH}$ at $2.71 \mathrm{ppm}$ and $-\mathrm{CH}_{2}-\mathrm{SH}$ at $1.6 \mathrm{ppm} 1.5-1.8 \mathrm{ppm}$. Scaling factor is 1 and for the insets it is 64 . 